\title{
Augmenting agroecological urbanism : the intersection of food sovereignty and food democracy
}

\section{Resler, Megan}

2021

Resler , M \& Hagolani-Albov , S 2021 , ' Augmenting agroecological urbanism : the intersection of food sovereignty and food democracy ', Agroecology and Sustainable Food Systems, vol. 45 , no. 3 , pp. 320-343 . https://doi.org/10.1080/21683565.2020.1811829

http://hdl.handle.net/10138/333444

https://doi.org/10.1080/21683565.2020.1811829

acceptedVersion

Downloaded from Helda, University of Helsinki institutional repository.

This is an electronic reprint of the original article.

This reprint may differ from the original in pagination and typographic detail.

Please cite the original version. 


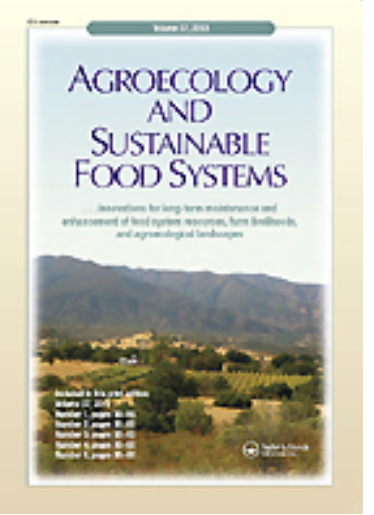

\section{Augmenting agroecological urbanism: The intersection of food sovereignty and food democracy}

\begin{tabular}{|r|l|}
\hline Journal: & Agroecology and Sustainable Food Systems \\
\hline Manuscript ID & WJSA-2019-0530.R1 \\
\hline Manuscript Type: & Original Article \\
\hline Keywords: & $\begin{array}{l}\text { food democracy, agroecological urbanism, urban agroecology, food } \\
\text { sovereignty, food system }\end{array}$ \\
\hline
\end{tabular}

\section{SCHOLARONE Manuscripts}



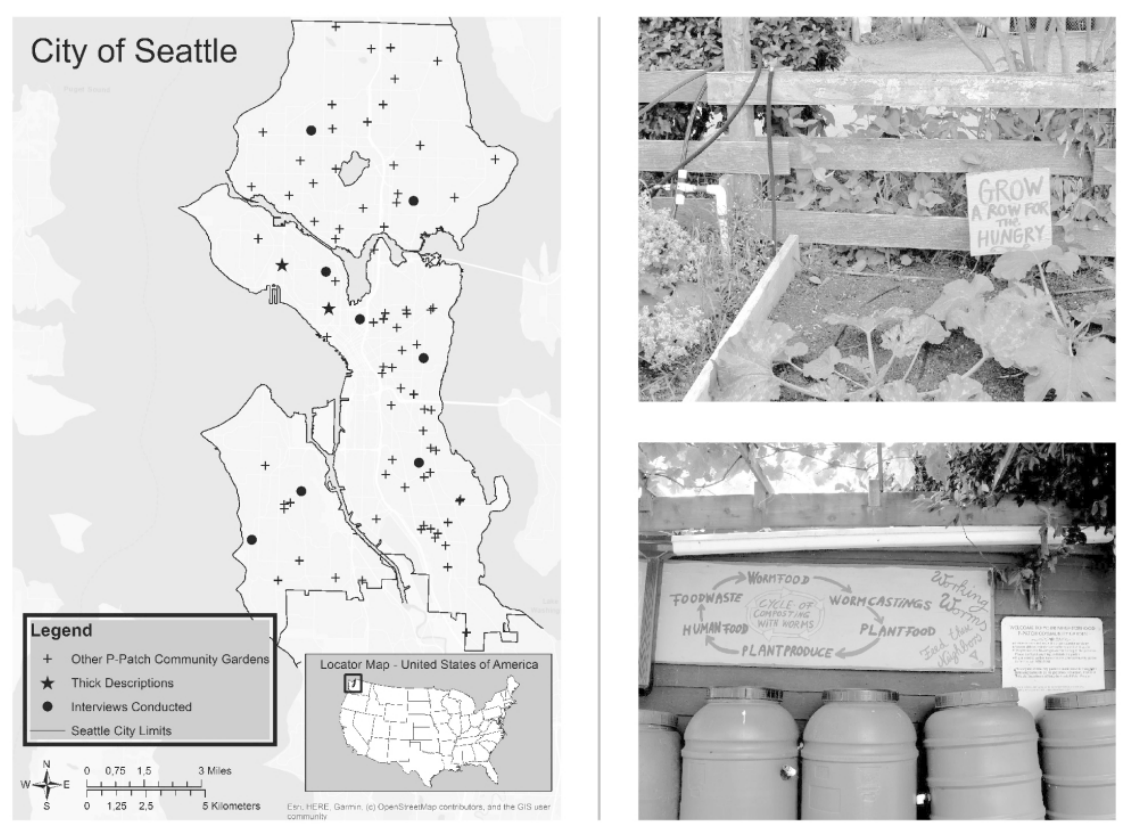

Figure 1: Spatial distribution of the P-Patch gardens across the GSR (Seattle GeoData 2018) paired with photos from two P-Patch gardens, which illustrate the interconnected nature of multiple pillars/key dimensions embodied in on-the-ground practice. In this case, narratives of Knowledge, Re-skilling, Common good, Need for food, Collaboration, Agroecological, and Efficacy are visible between the two images.

$$
190 \times 130 \mathrm{~mm}(300 \times 300 \mathrm{DPI})
$$




\section{Food Sovereignty:}

Representation of FS and FD across the data sets

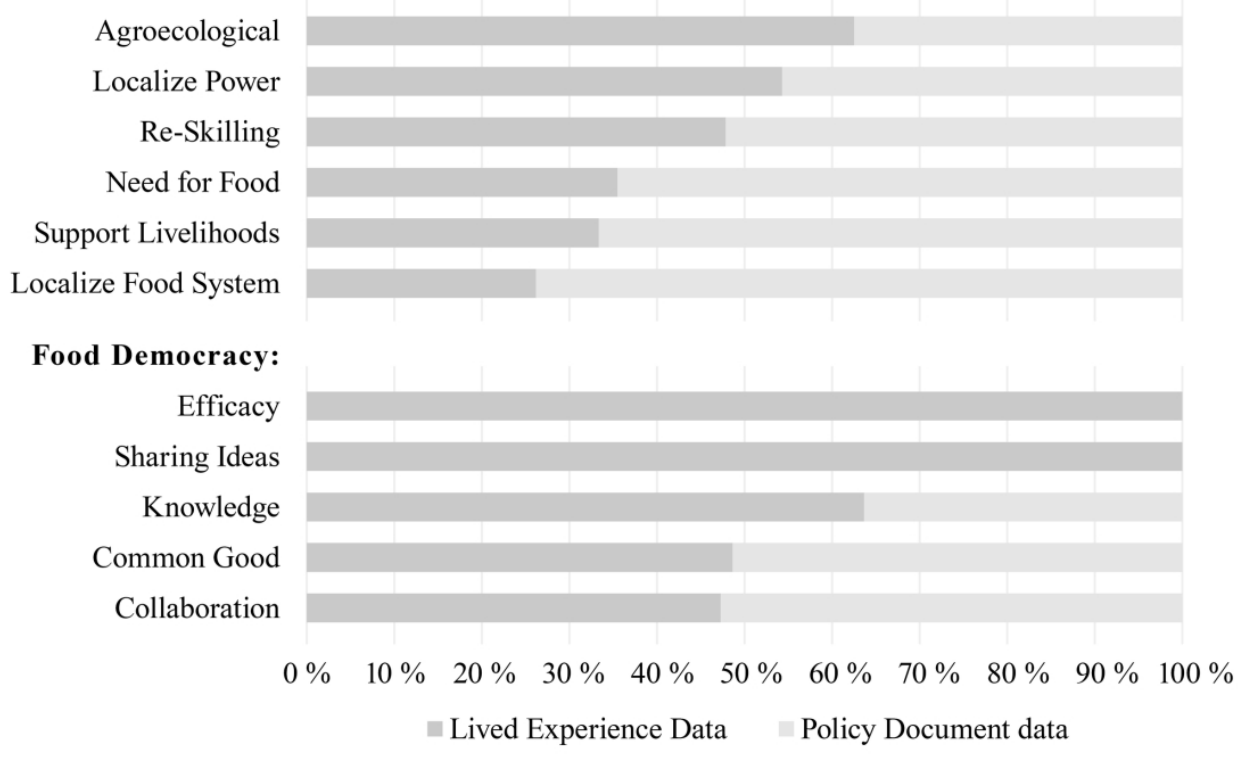

Figure 3: Prevalence of embodied examples of pillars of food sovereignty and key dimensions of food democracy represented across both the lived experience and municipal public policy data.

$211 \times 143 \mathrm{~mm}(300 \times 300 \mathrm{DPI})$ 


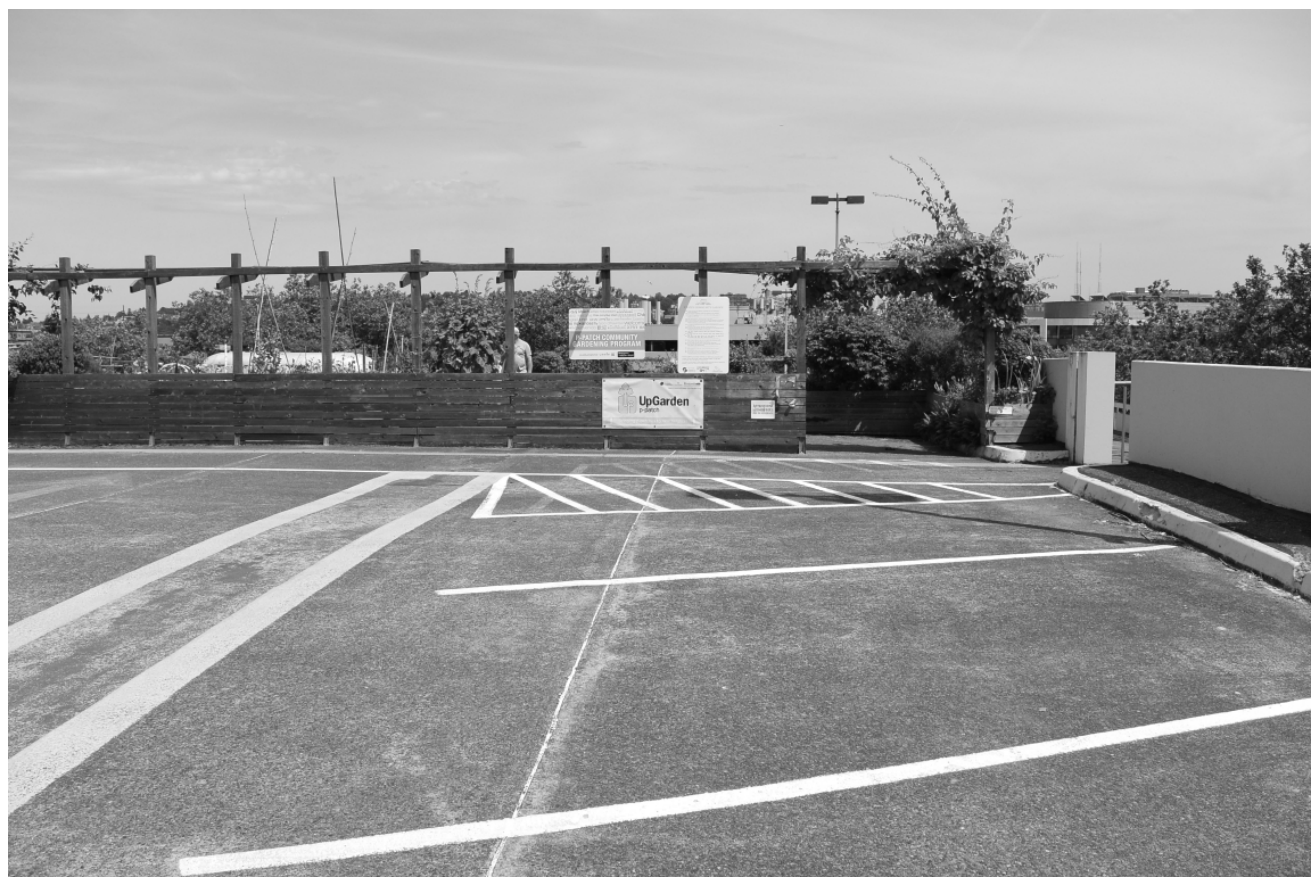

Photo 1: Entrance to the UpGarden P-Patch, located on top of the Mercer St. Parking Garage in downtown Seattle, U.S.A.

$1625 \times 1083 \mathrm{~mm}(72 \times 72 \mathrm{DPI})$ 


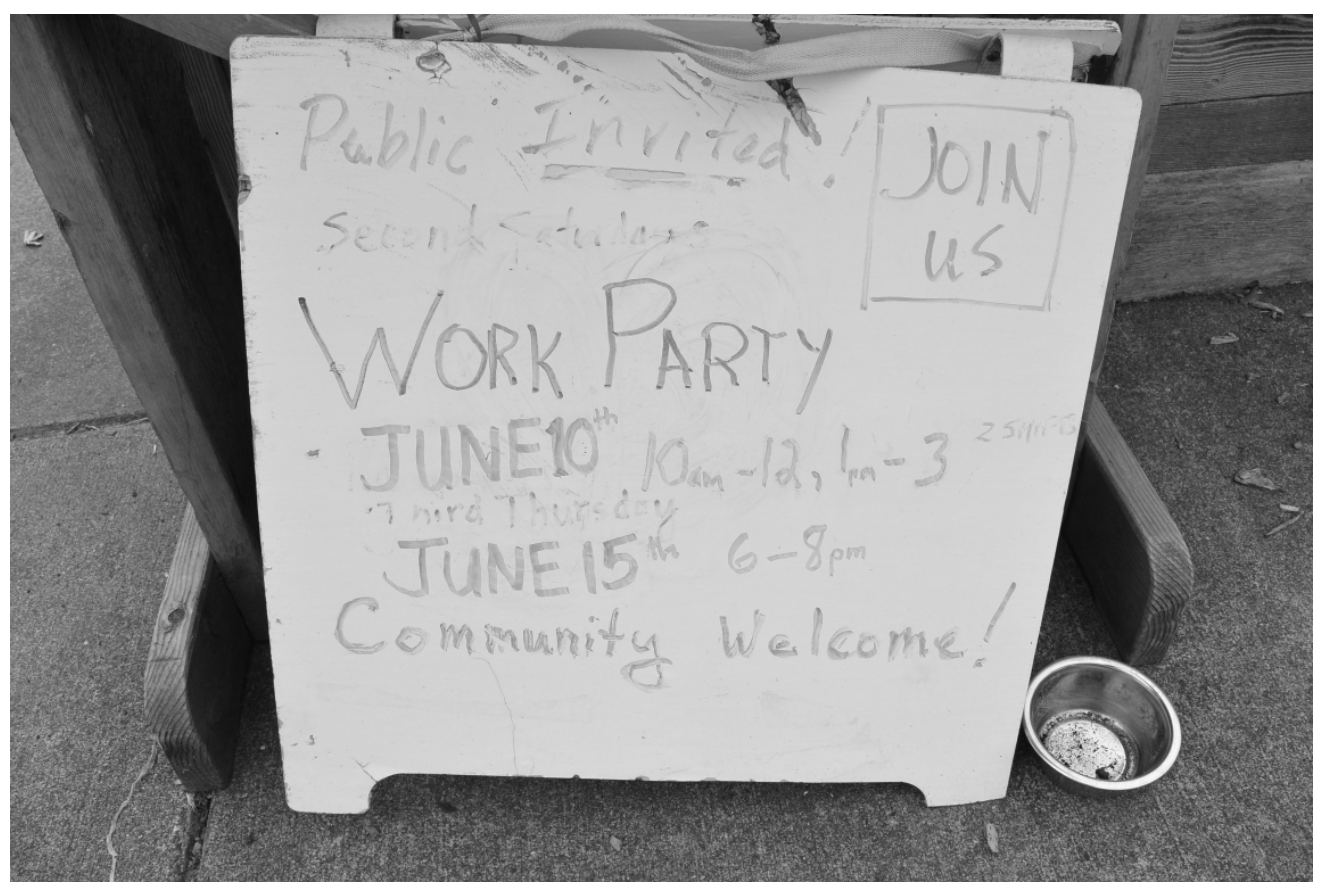

Photo 2: Welcome sign inviting community members to join in weekly work parties at Interbay P-Patch. $1625 \times 1083 \mathrm{~mm}(72 \times 72 \mathrm{DPI})$ 
Table 1: The characterization of each key dimension of FD and pillar of FS utilized in the coding scheme.

\begin{tabular}{|c|c|c|}
\hline \multicolumn{3}{|c|}{ Coding scheme implemented across both data sets } \\
\hline \multirow{6}{*}{\begin{tabular}{|} 
Six pillars of \\
Food \\
Sovereignty \\
(Gordilla and \\
Jeronimo \\
$2013, \mathrm{~V})$
\end{tabular}} & Localize Power & $\begin{array}{l}\text { Strengthening control at a local level, through a) empowering local food } \\
\text { suppliers; b) acknowledging the necessity of inhabiting and sharing } \\
\text { territories; and c) refusing the privatization of natural resources }\end{array}$ \\
\hline & Re-Skilling & $\begin{array}{l}\text { Promotion of knowledge and skills, through a) strengthening traditional } \\
\text { environmental knowledge; b) investing in research; c) pass knowledge } \\
\text { along to future generations; and d) in refusing the technologies and } \\
\text { processes of specialized industrial agriculture }\end{array}$ \\
\hline & Agroecological & $\begin{array}{l}\text { Works with nature by: a) maximizing the contributions of ecosystems; } \\
\text { b) improving resilience; and c) rejecting energy intensive, monocultural, } \\
\text { industrialized and destructive production methods }\end{array}$ \\
\hline & Need for Food & $\begin{array}{l}\text { Focuses on food for the people by: a) placing people's need for food at the } \\
\text { center of policies; and b) insisting that food is more than just a commodity }\end{array}$ \\
\hline & $\begin{array}{l}\text { Localize Food } \\
\text { System }\end{array}$ & $\begin{array}{l}\text { Localizes food systems by: a) reducing the distance between suppliers and } \\
\text { consumers; b) rejecting dumping and inappropriate food aid; and } \\
\text { c) resisting dependence on remote and unaccountable corporations }\end{array}$ \\
\hline & $\begin{array}{c}\text { Support } \\
\text { Livelihoods }\end{array}$ & $\begin{array}{l}\text { Values food providers by: a) supporting sustainable livelihoods; and } \\
\text { b) respecting the work of all food providers }\end{array}$ \\
\hline \multirow{5}{*}{$\begin{array}{c}\text { Five key } \\
\text { dimensions of } \\
\text { Food } \\
\text { Democracy } \\
\text { (Hassanein } 2008)\end{array}$} & Efficacy & $\begin{array}{l}\text { Individuals gaining confidence, and momentum, in their capacity to have } \\
\text { success with respect to food and food system }\end{array}$ \\
\hline & Deliberation & $\begin{array}{l}\text { Ongoing discussion, deliberation, and the sharing of ideas which allows } \\
\text { citizens to clarify issues and negotiate common values }\end{array}$ \\
\hline & Collaboration & $\begin{array}{l}\text { Collective action by and among organizations, toward food system } \\
\text { sustainability }\end{array}$ \\
\hline & Common Good & $\begin{array}{l}\text { Citizens acquiring an orientation toward the community good by moving } \\
\text { beyond their self-interests }\end{array}$ \\
\hline & Knowledge & Citizens acquiring broad knowledge of the food system \\
\hline
\end{tabular}


Table 2: This matrix acts as a guide and a simplified expression for the four subsections in the discussion.

\begin{tabular}{|c|c|c|}
\hline Across Data Sets & Pillars of FS & Key dimensions of FD \\
\hline Superimposed & $\begin{array}{c}\text { Finding 1: } \\
\text { Localize Power; Re-Skilling }\end{array}$ & $\begin{array}{l}\text { Finding 2: } \\
\text { Collaboration; Common } \\
\text { Good; Knowledge }\end{array}$ \\
\hline Divergent & $\begin{array}{l}\text { Finding 3: } \\
\text { Need for Food; Localize Food System; } \\
\text { Support Livelihoods; Agroecological }\end{array}$ & $\begin{array}{c}\text { Finding 4: } \\
\text { Efficacy; Deliberation }\end{array}$ \\
\hline
\end{tabular}




\title{
Augmenting agroecological urbanism:
}

\section{The intersection of food sovereignty and food democracy}

\author{
Anonymous Version
}




\title{
Word Count \\ $8965(9,117$ in non-anonymous version)
}

\begin{abstract}
Food sovereignty has emerged as a leading sense-making framework for the nascent conceptualization of an agroecological urbanism — a radically new paradigm for urbanization, grounded in political agroecology. At present, discourses like food democracy are often isolated from food sovereignty and agroecology in the urban context, potentially resulting in missed opportunities for creating holistic, inclusive, and scalable transformation in the urban food system. This study used data from existing municipal food policy in Seattle, U.S.A. and interviews with Seattle community gardeners to probe resident practices and policy recommendations in relation to the conceptual frameworks of food sovereignty and food democracy. The findings identify two key dimensions of food democracy as notably absent from the food sovereignty framework within this contextualized landscape, including mechanisms that enable vertical deliberation between food system stakeholders and opportunities for strengthened self and community efficacy - thus, exposing a potential gap in the ongoing development of an actionable agroecological urbanism. Working in tandem within the frame of agroecological urbanism, the food sovereignty and food democracy frameworks may support transition from unsustainable growth patterns and enable agroecological massification in an urban Global North context.
\end{abstract}

\section{Keywords}

Food democracy; food sovereignty; urban agroecology; agroecological urbanism, food systems; agroecology

\section{Introduction}

With an unprecedented majority of the global population residing in cities, a figure that is predicted to rise to two-thirds of the total population by 2050 , issues of hunger and food security are widely pressing (UNHabitat 2016). Immediate interventions across a range of socio-political leverage points are required to work towards transformative food system changes that adequately suit urbanizing areas (Abson et al. 2017; Meadows 1999). A growing body of research evidences the capacity of agroecology to merge practicebased perspectives, academic expertise, and stakeholder knowledge to address these wicked food system challenges across global, national, and territorial scales (Bouma et al. 2011; Mendez et al. 2013; Wezel et al. 2014; Gliessman and Engles 2015; Gliessman and Tittonell 2015). 
While dominant agroecology discourse continues to consider the integration of diversified farming practices within a rural context, notable contributions have emerged in the development of an urban-centric agroecology (Rosset and Martinez-Torres 2012; Tornaghi 2017; Deh-Tor 2018; Tornaghi and Dehaene 2020). The existing dialogue around the socio-cultural facet of urban agroecological practice frequently hinges on the conceptual framework of food sovereignty (Deh-Tor 2018; García-Sempere et al. 2018; García-Sempere et al. 2019; Vaarst et al. 2018). While the food sovereignty framework is a powerful articulation of agroecological ideals emerging from rural social movements, we argue that it does not comprehensively describe the lived experience of the urban agricultural practitioners encountered in our case study. Thus, this research further develops the paradigm of a distinctly urban agroecology through the integration of certain key dimensions of the concept of food democracy with the existing conceptual framework of food sovereignty that runs consistently through the nascent conceptualization of agroecological urbanism. See Table 1 for an expanded explanation of how these dimensions were interpreted for our coding scheme and thematic analysis.

This research probes the Greater Seattle Region (GSR) in the Pacific Northwest of the United States, as a living example of a region where the pillars of food sovereignty and key dimensions of food democracy mesh to build a robust urban agricultural landscape (see Map 1). In building deliberate linkages in the theoretical conversations surrounding food sovereignty and food democracy, this work synthesizes experiential knowledge from engaged food citizens with existing public municipal policy recommendations aimed at strengthening regional food systems. We draw from the lived experience of the urban agricultural practitioner to illustrate the depth and breadth of practices occurring on-the-ground, as well as the public municipal policies in place that work to shape power dynamics across the urban agricultural landscapes.

This article proceeds with a brief overview of the concepts of food sovereignty and food democracy and their current relationship to the concept of agroecological urbanism. This is followed by a discussion of the methods used in the data collection and analysis. Then, a contextual sketch of the GSR provides foregrounding for the data and findings. We introduce our interview data using a set of two thick descriptions. Next, we explore the findings, which integrate the analysis of the interview data and the policy documents. We then use empirical evidence to articulate how the pillars of food sovereignty and key dimensions of food democracy manifest within the contextually bound GSR. Lastly, we conclude with an indication of the need for further research into these pertinent questions in varied urban contexts. Our proposed augmentation of the conceptualization of agroecological urbanism, in support of developing an 
actionable urban political agroecology, has implications and applicability for urban gardening practitioners, policy makers, and urban planners.

\section{Framing food sovereignty and food democracy in agroecological urbanism discourse}

Agroecology is a holistic and ecological approach to food systems that encompasses the biophysical, sociocultural, and political aspects of food systems (Helenius, Wezel, and Francis 2019; Francis et al. 2003). The approach engages alternative forms of agricultural practice that work in conjunction with natural systems and stands in direct opposition to the strategies of the specialized industrial agriculture food chain (Altieri 2018). Agroecology as a social movement has historically grown out of, and has been strongly associated with, the socio-cultural aspects, perspectives, and roles in movement building in support of just rural farming practices in the Latin American context (Nicholls and Altieri 2018). As such, it is important to be deliberate when transferring the principles of agroecology to an urban/North American setting (Nicholls and Altieri 2018; Lamine and Dawson 2018).

Furthermore, agroecology is rapidly spreading from its disciplinary roots in agricultural sciences to other fields/disciplines through the adoption of the principles of agroecology as they relate to agricultural transition and sustainable food production and provisioning (Holt-Giménez and Altieri 2018; Gliessman 2018). One professional discipline that has embraced agroecology is urban planning, with specific attention to the socio-cultural aspects of agroecology as they relate to just and sustainable food systems (Vaarst et al. 2018). In recent years, developing conceptualizations of the terms urban agroecology and agroecological urbanism have sparked a lively dialogue between the professional discipline of urban planning and the scientific discipline of agroecology, often drawing from the pillars of food sovereignty as an avenue through which individuals can achieve equitable and sustainable interactions with their food systems (Deh-Tor 2018).

Food sovereignty is a central concept in food systems transformation literature, particularly in response to the global food crises of the early 21 st century (Rosset 2008). In accordance with agroecological principles and practices, food sovereignty refers to the right/agency a population should have to define the composition of their own food system (Nyéléni Declaration 2007). Food sovereignty is prominent in both action and discourse related to rural agency building, food system transition, and peasant resistance, especially through La Vía Campesina (Patel 2009). Yet, there is a gap in our understanding of food sovereignty as it is applied to urban food systems, as was recently highlighted by García-Sempere et al. (2018). This gap is rapidly closing as more research is done to articulate the linkages and the role that the 

movements and food justice in urban environments in the Global North. Notably, García-Sempere et al. (2019) contributes a framework of indicators useful to the evaluation of food sovereignty within an urban Global South context. The authors acknowledge, however, that their framework neglects to include indices which consider group processes or collective action at a regional scale, including municipal public policies and urban-rural linkages (García-Sempere et al. 2019).

As the nascent conceptualization of agroecological urbanism continues to develop, we notice a tendency in the literature to focus on food sovereignty to describe the set of social and cultural actions that occur within the system (Deh-Tor 2018; Tornaghi 2014; Mendez et al. 2013). While food sovereignty is a vital organizing mechanism of the socio-cultural function of an urban system rooted in agroecological thinking (i.e. an agroecological urbanism), we argue that it does not consider a sub-section of community-level interactions that are present in the lived experiences of urban agriculture practitioners -- thus, limiting the capacity of grassroots engagement and momentum to translate into transformative policy change in an urban context in the Global North.

On the surface, the overarching definition of food democracy is very closely related to the definitions of food sovereignty, food citizenship, and other concepts based around developing a just food system. As with all of these concepts, food democracy is layered in meaning and application, however, it directly addresses group level processes vital to developing socio-culturally and politically relevant food systems (Hassanein 2003, 2008). A recent and concise conceptualization stresses that, "Food democracy seeks to organize the food system so that communities can participate in the decision-making, can see the ecological risks and benefits to food system choices, and can respond collectively and accordingly," (Carlson and Chappell $2015,6)$. However, it is in operationalizing the concept and particularly in connecting the key dimensions to on-the-ground actions where the concept gains additional meaning.

In integrating certain key dimensions of food democracy that serve to expand the capacity of communitylevel intervention to the agroecological urbanism framework, the two work to complement and reflect aspects of lived experience that are not explicitly articulated by food sovereignty in isolation. Food sovereignty and food democracy are not opposing concepts; they work together in providing a frame for creating more equitable food systems. Both concepts work toward development of justice and strengthened localized food systems, and in some cases the terms are either conflated or used interchangeably. However, 
a surface-level exploration of these terms neglects to acknowledge key nuances between these continually evolving concepts (Hassanein 2008). At its foundation, food democracy is designed to enable a range of community-level processes of deliberation that García-Sempere et al. (2019) have identified as a gap in food sovereignty's role in food system transformation. Food democracy holds the potential to work in concert with food sovereignty to support transformation in urban agricultural practice (Chiffoleau, MilletAmrani, and Canard 2016). Through this focus on community level process, food democracy operates as a bridge for urban food producers in translating discreet, on-the-ground practice, into an actionable path towards food system transformation. Without the direct integration of key facets of food democracy, the developing conceptualization of an agroecological urbanism runs the risk of isolating actionable and innovative community level processes from influencing local policy related to the makeup of the local food system.

\section{Methodology}

Research context: Seattle, U.S.A.

With a population of 744,966 Seattle is the most densely populated city in Washington State (United States Census Bureau 2018). Identified as the United States' fastest growing city in July 2016, the recent densification and regional sprawl of the GSR has contributed to increased regional poverty, homelessness, and food insecurity (United States Census Bureau 2018). Of all GSR residents, 13 percent of adults and 22 percent of children reside in food-insecure households (King County 2008). In response to these contextualized, social, and spatial challenges, municipal agencies within the City of Seattle and King County have acted to strengthen the local agricultural landscape and promote inclusive food access among constituents. Municipal policy articulations, which harness government planning and policy resources, have contributed to Seattle's recognition as a "community of innovation" in local food policy by the FAO (Cabannes and Marocchino 2018). 

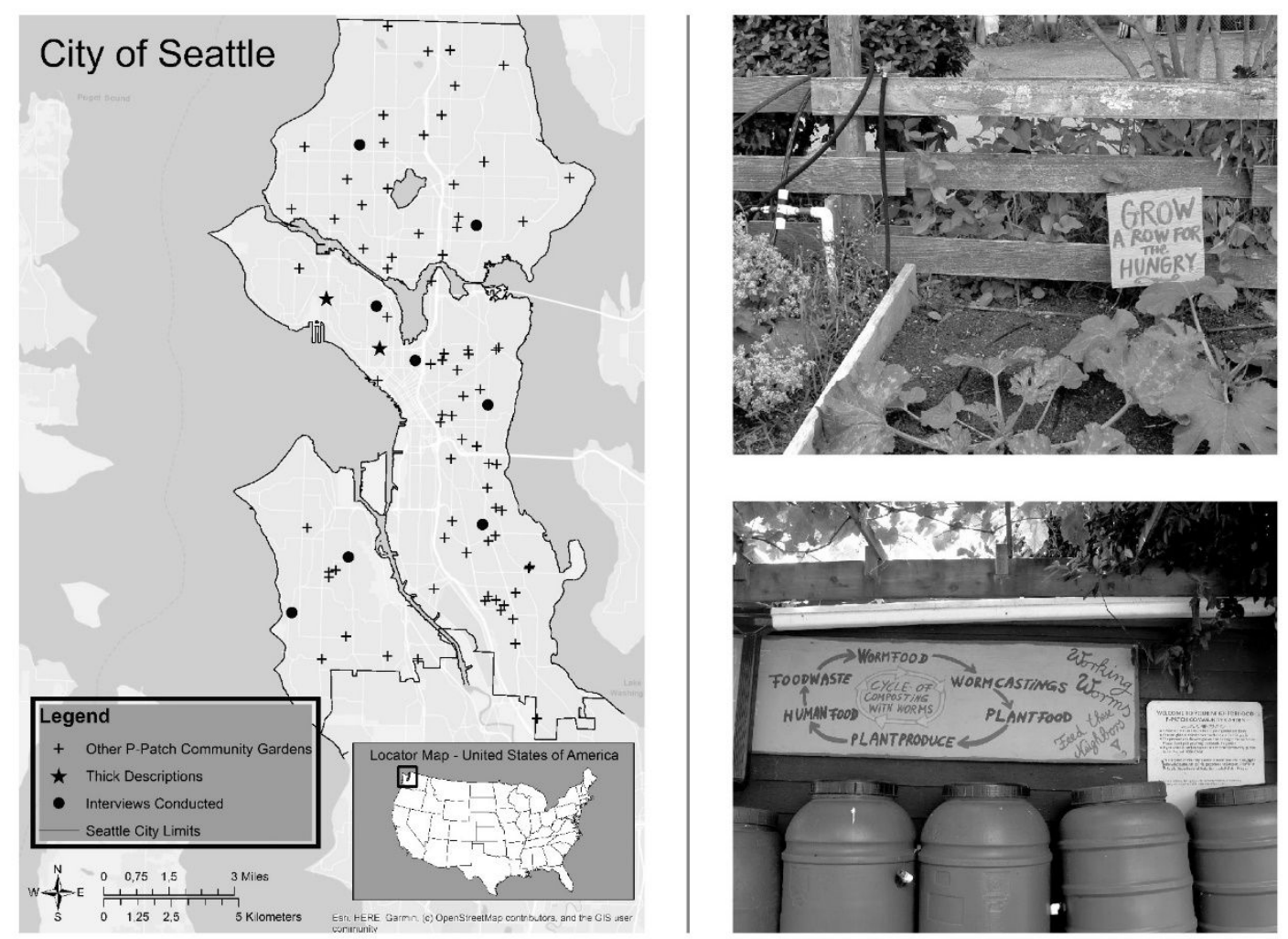

Figure 1: Spatial distribution of the P-Patch gardens across the GSR (Seattle GeoData 2018) paired with photos from two P-Patch gardens, which illustrate the interconnected nature of multiple pillars/key dimensions embodied in on-the-ground practice. In this case, narratives of Knowledge, Re-skilling, Common good, Need for food, Collaboration, Agroecological, and Efficacy are visible between the two images.

\section{Data collection: Interviews, observation, and policy documents}

We employed an interdisciplinary approach to this research methodology, drawing from the disciplines of agroecology, urban planning, and human geography. Our data speaks to both individual lived experience of the urban agricultural practitioner and current food policy recommendations in the municipality. The qualitative methods of data collection employed in this research include: 1) a series of ten semi-structured interviews and participant observation with urban gardeners from the P-Patch Community Gardening Program in Seattle, USA; and 2) a review of two regional municipal food policy documents from the City of Seattle and King County, which falls within the GSR but extends beyond the borders of the city itself. 
The interview and participant observations were conducted in Seattle's P-Patch urban gardens, managed by the City of Seattle Department of Neighborhoods, during the summer of 2017. The systematic orientation towards organic cultivation in the P-Patch Program serves to indirectly support aspects of agroecological production methods, extending across 90 gardens, 3,055 plots, and more than 6,800 gardeners (P-Patch Community Garden, 2019). Interview candidates were chosen based on a series of discrete criteria including: 1) self-identification as urban food producer; 2) participation as an active member of the P-Patch Program; and 3) over the age of 18. A call for participation was distributed via the Seattle P-Patch Community Gardening network's email listserv, with the assistance of the Seattle Department of Neighborhoods.

The two regional municipal food policy documents included in this research are the Local Food Action Initiative City of Seattle Resolution 31019 initially passed in 2008 (King County 2008) and the City of Seattle 2012 Food Action Plan (Lerner 2012). These documents relate the local food systems by way of articulating the goals, policy frameworks, and specific action recommendations which can strengthen the local and regional food systems (Lerner 2012; King County 2008). The P-Patch gardens themselves are an integral facet of the initiatives described in the City's Food Action Plan, however, the food action plan itself is not the direct funding mechanism for the gardens (Lerner 2012). Given the meta-level of strategy addressed in both policy documents, they stand as an insight into the position and relevance of local food systems in this city and region. Furthermore, we chose to include this set of documents within our research material because they are in active use at the time of writing, and in combination, speak for the totality of the territories included in the P-Patch Program's network of gardens.

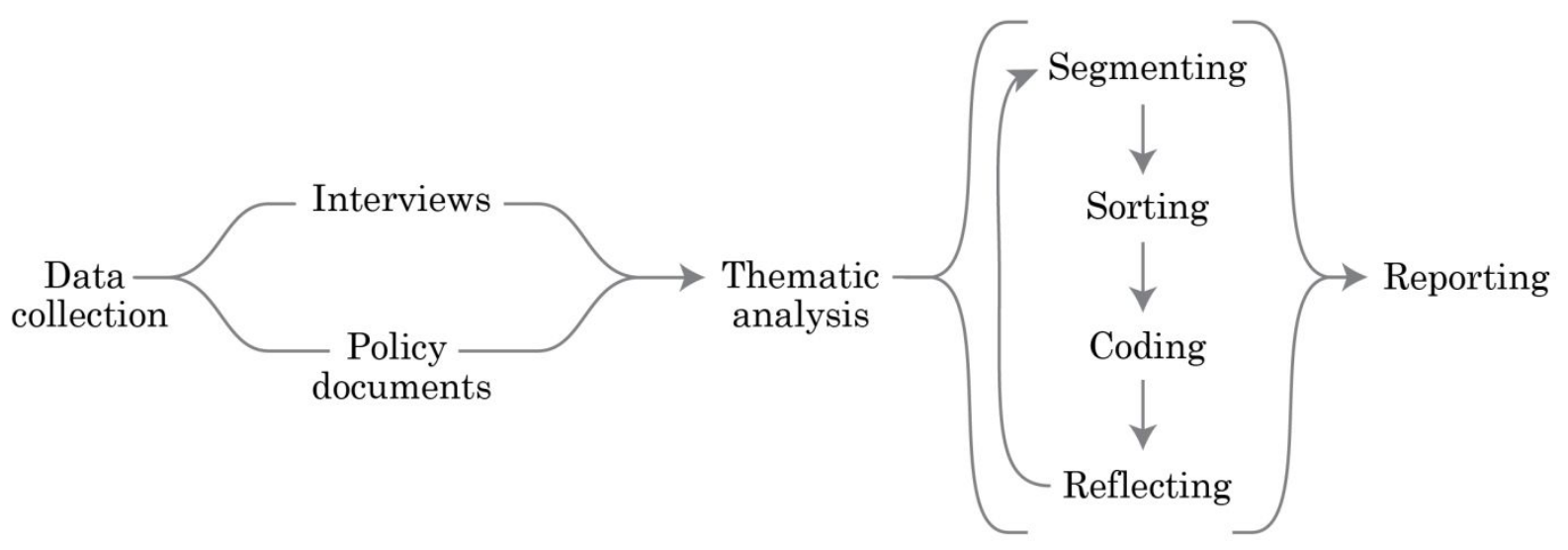

Figure 2. This is a visualization of the methods flow of our research design. Both data sources were analyzed using the same iterative process and coding scheme. 
The interview and participant observation data were analyzed alongside the textual content of the policy documents using computer assisted qualitative data analysis software. Two interviews were chosen to inform the thick descriptions included in this article. We employed a series of structured processes to segment, sort, and categorize both sets of empirical data, thus probing practitioner lived experience in relation to regional policy recommendations. Adhering to the structural protocol of the qualitative analysis cycle (Miles and Huberman 1994), we adopted a thematic analysis approach to pattern-seeking within our data. Thematic analysis was chosen for its suitability with interview data and other text-driven data sources, specifically its capacity to identify associations between clusters of themes, and its compatibility with our abductive approach to reasoning (Denzin 1994; Boyatzis 1998). Mirroring the mixed and iterative methods approach employed by Cristofari et al. (2018) we engaged with an abductive approach to reasoning. We draw directly from the FAO's (Gordilla and Jeronimo 2013) characterization of the six pillars of food sovereignty and Hassanein's (2008) five key dimensions of food democracy to inform our coding scheme (see Table 1). Conclusions were verified using if-then tests within the coding software and triangulated across an iterative coding scheme.

Table 1: The characterization of each key dimension of food democracy and pillar of food sovereignty utilized in the coding scheme.

\begin{tabular}{|c|l|l|}
\hline \multicolumn{3}{|c|}{ Coding scheme implemented across both data sets } \\
\hline \multirow{2}{*}{$\begin{array}{c}\text { Six pillars of } \\
\text { Food }\end{array}$} & Localize Power & $\begin{array}{l}\text { Strengthening control at a local level, through 1) empowering local food } \\
\text { suppliers; 2) acknowledging the necessity of inhabiting and sharing } \\
\text { territories; and 3) refusing the privatization of natural resources }\end{array}$ \\
\cline { 2 - 3 } $\begin{array}{c}\text { Sovereignty } \\
\text { (Gordilla and } \\
\text { Jeronimo } \\
2013, \text { V) }\end{array}$ & Agroecological & $\begin{array}{l}\text { Promotion of knowledge and skills, through 1) strengthening traditional } \\
\text { environmental knowledge; 2) investing in research pass knowledge along } \\
\text { to future generations; and 3) in refusing the technologies and processes of } \\
\text { specialized industrial agriculture }\end{array}$ \\
\cline { 2 - 4 } & Need for Food & $\begin{array}{l}\text { Works with nature by: a) maximizing the contributions of ecosystems; } \\
\text { b) industrialized and destructive production methods }\end{array}$ \\
\cline { 2 - 4 } & $\begin{array}{l}\text { Focuses on food for the people by: a) placing people's need for food at the } \\
\text { center of policies; and b) insisting that food is more than just a commodity }\end{array}$ \\
\hline
\end{tabular}




\section{Communicating the findings: Thick description of practitioner lived experience}

Drawing inspiration from WinklerPrins (2005) and Bissell and Gorman-Murray (2019), we use the narrative style of thick description to convey the findings of the empirical interview data. These descriptions illustrate the lived experiences of two gardeners from two different municipally-sponsored urban gardens in the Seattle P-Patch network. This technique of communicating the data is intended to provide the reader with a deeper understanding of the lived experience and sense of place articulated by the interview participants. These descriptions illustrate, in part, the embodied actions and expressions of the FAO's (Gordilla and Jeronimo 2013) characterization of food sovereignty, as well as the key dimensions of food democracy as articulated by Hassanein (2008). Bolded text are examples of the pillars of food sovereignty and key dimensions of food democracy embodied in practice.

Debi: UpGarden P-Patch 


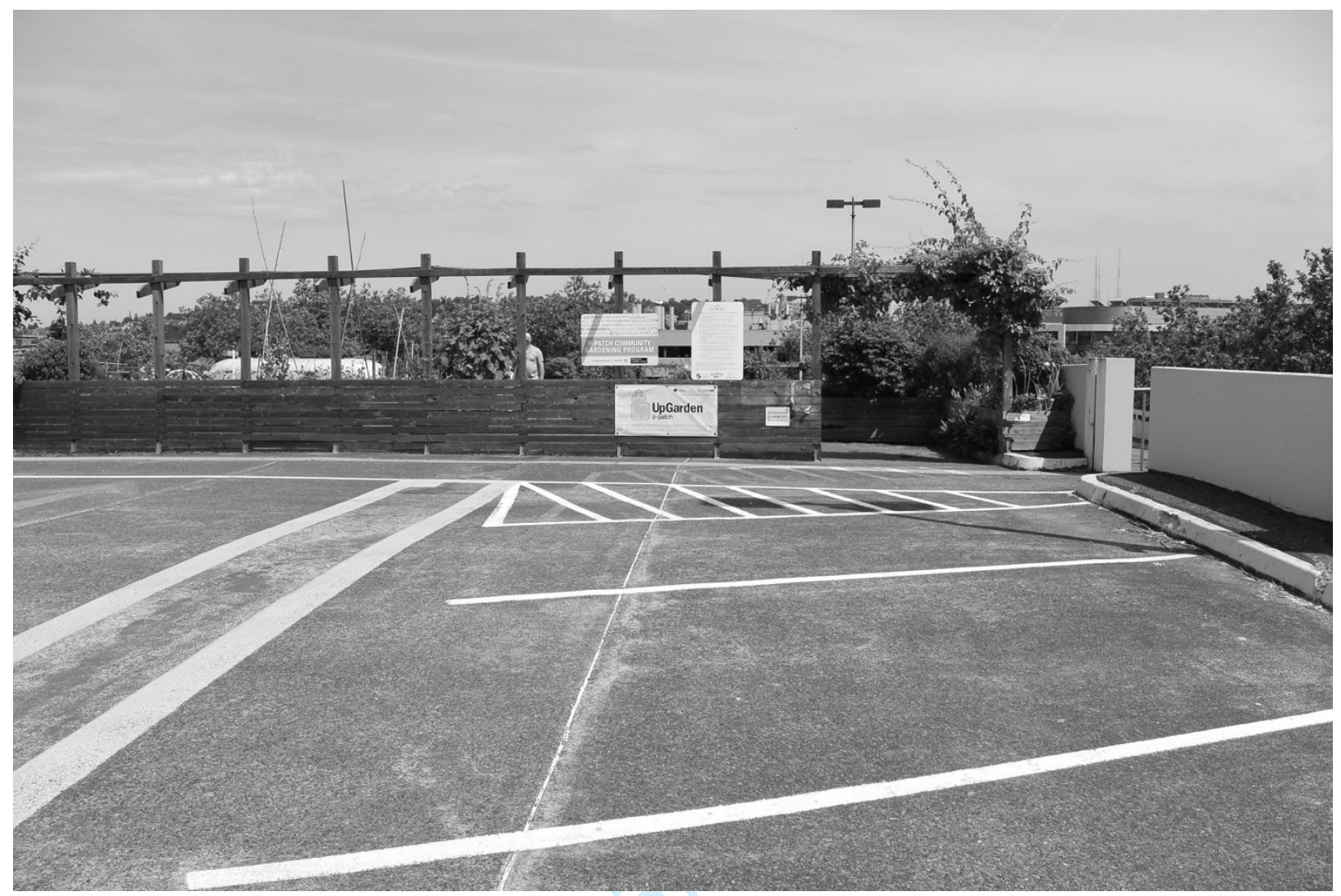

Photo 1: Entrance to the UpGarden P-Patch, located on top of the Mercer St. Parking Garage in downtown Seattle, U.S.A.

Convinced I am in the wrong place, I hesitantly continued to climb the stairs to the top of the 5 story Mercer St. Parking Garage, located adjacent to one of downtown Seattle's busiest thoroughfares. Reaching the roof, I see a grey ramp with approximately 100 empty parking spots, and the Mercer St. UpGarden P-Patch sign - along with trellises of grape vines, rows of blossoming flowers and edible plants.

Immediately upon meeting Debi (name changed to protect the privacy of the respondent) I liked her. She reminded me, somehow, of my own grandmother, she radiated warm gentleness. Debi pulled up two lawn chairs for us and described how she came to be involved at this garden. She explained that she was one of the members of the planning group who built this P-Patch in 2012. "We began the planning in November 2011...Twenty of us built this garden." She was the first P-Patcher I had interviewed that was involved with the development of a new Patch. "This is a very transient garden because we're in the middle of "tech world" here. So, there's a lot of changes. Most P-Patches, you will find the majority of the people [gardening there] to be middle-aged and higher. This P-Patch, they are young. We have lots of young people who have never gardened before, so we are constantly teaching up here." 
Debi continued to describe the work parties they host every weekend in the spring and fall, attended by volunteers and plot-tenders to fulfil their compulsory volunteer work. "Everybody has to do 8 hours a season of volunteer work for the common beds... We have a lot of people who volunteer that time in the Giving Garden. Last year we donated over 1,000 pounds of organically grown food to the food banks from this garden. It's truly amazing." In addition to volunteering time for the common good through the Giving Garden, Debi explained that their Patch has an established Gleaning team. She shared an example of that work, “if someone plants a row of lettuce and can't eat it all... or if people are on vacation and know their tomatoes are going to get ripe while they're gone, they tell us and we harvest... and donate [the produce] to the food banks. We have sticks that say 'Share' on them and... they can stick that in their plot and then we observe that and harvest. We did over 200 pounds last year through gleaning."

While Debi talked, I realized that it was very quiet in the garden, especially compared to a few stories down at the street level. A Red Breasted Robin perched atop a pole in Debi's plot. The most startling disorientation was being surrounded by the midpoint of skyscrapers. A garden amongst all the steel and glass.

Debi mentioned that she periodically leads workshops for teen groups from a nearby high school in the garden: "This last spring during Earth Day I told [a teen group] about how we build our ecosystem here and I talked to them a lot about diversity... from nutrition in the soil all the way to the variety of people that you need for a community garden to work." She went on to elaborate that she volunteers her time in leading children's day camps in the P-Patch with groups from the Children's Museum, Pacific Science Center, and the Seattle Public School District.

We walked past the plot tended by students from the nearby High School and Debi shared, "we average probably forty kids a week in the summertime, and sixty high schoolers through a season. Then we've formed a relationship with the senior residential center not far from here. They have a greenhouse. Some of the ladies there grow our starts [seedlings] for the Giving Garden and our children's garden, in their greenhouse...The physical therapist...there uses the garden as a destination point for working with people in physical therapy." Combining her time volunteering in the Giving Garden, on the Gleaning team, and teaching workshops and day camps for children and teens, Debi estimated that she has donated over 500 hours of time to her P-Patch this year.

A younger person waved at Debi from across the garden. This was one of the two teen volunteers she met weekly, and signaled the end of our interview. Before we parted ways, I asked Debi if she could summarize why she gardens. "Being disabled takes a lot of self-worth out of you. [When gardening] I can be successful 
even though I'm disabled...They call me the Gardening Grandma up here," she explained with a smile, "I get to interact with lots of people... It can be hard to make friends in this city with all of us in our high buildings with our closed doors, but up here we all have something in common. So, my community is so much greater here than it was before the garden. And every time you nurture something, it builds your own soul. And not only do I get to nurture plants and animals, I get to nurture children and teens and adults. For me it's a really important part of who I am. That's a really important piece of me. It gives me my sense of value." [Seattle, USA June 2017]

\section{Liz: Interbay P-Patch}

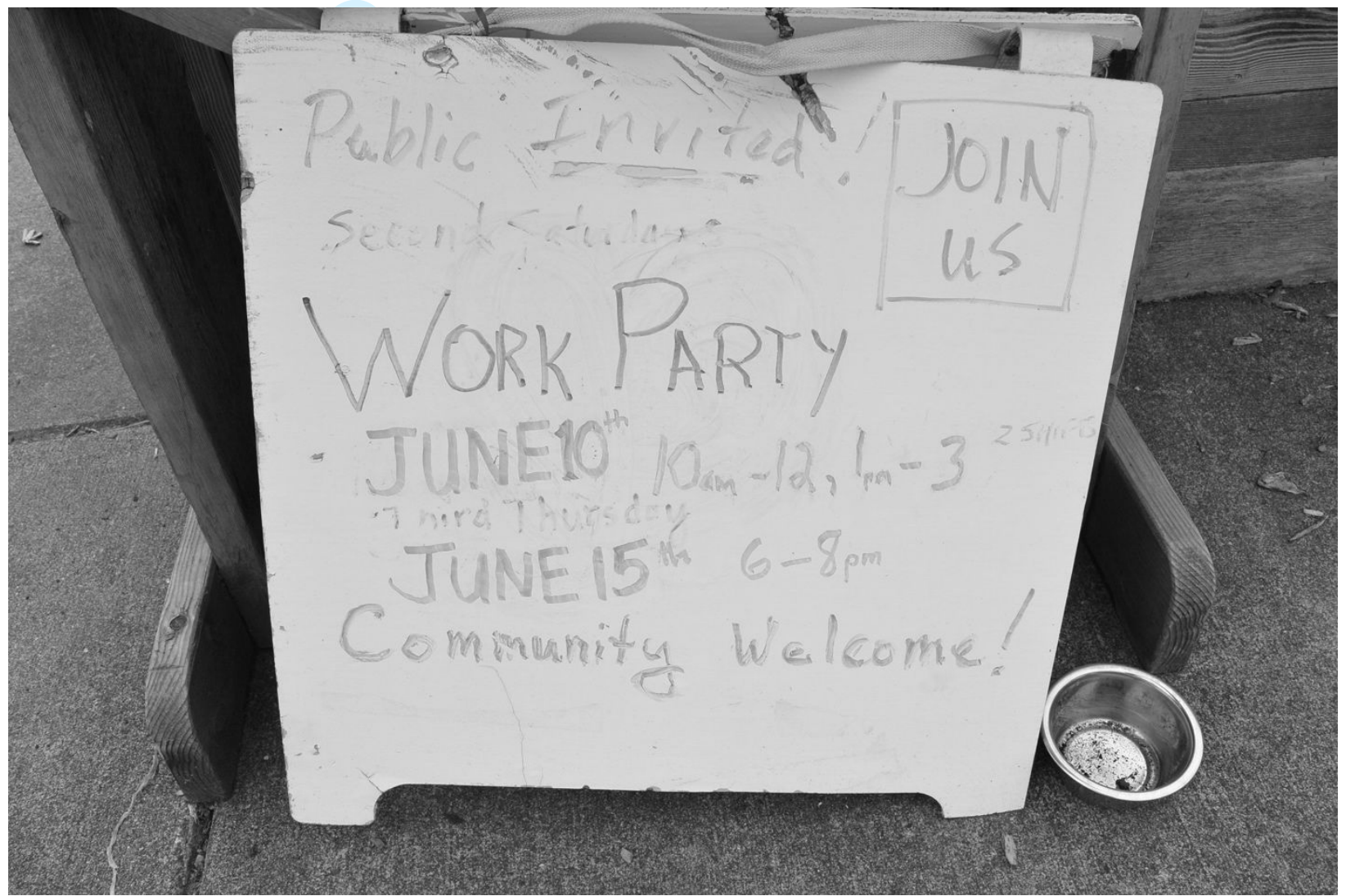

Photo 2: Welcome sign inviting community members to join in weekly work parties at Interbay P-Patch.

The phone rang a few times and Liz picked up; while we could not meet in person for the interview, I had previously visited Liz's garden plot. I inquired how Liz came to be involved with the P-Patch network. "When I moved to Seattle in 2003, I didn't know anybody. I figured gardening was a good way to get into a community and meet people."

In previous written correspondence Liz had stated that she was the Giving Garden manager at Interbay. All my previous interviewees had described a similar Giving Garden at their P-Patch, often with pride, and 
embedded with impressive figures evidencing the weight of their donations of fresh, organic produce, to Seattle's rapidly-rising population of people in need. "Interbay P-Patch has one of the longest running Giving Gardens in the city. I think it's been in operation since the early 1980s. It's turned into quite a program," I could hear her warmth and admiration for the program.

Liz described how she came to oversee the program, "In 14 years I went from being a volunteer, to being a P-Patch groupie, to getting my own plot in the garden, and then running the Giving Garden program...This [P-Patch garden] is where I've learned to grow food." I inquired further about the volunteers who work in the Giving Garden. "We advertise at different times in local community papers, and people wander in and fall in love and volunteer. It's very much a community-building, friendship-making, exercise. We meet at 5:30 on Monday evenings, we do all the work that needs to be done, and then we have a little potluck outside... the gardeners don't need a lot of incentives to get here and eat and drink."

Liz described the Interbay P-Patch's historical commitment to hosting community compositing parties to improve soil health in the garden, with origins back to when the City of Seattle relocated the garden to make room for a golf course. "Everybody came, and they got deliveries of leaves and grass, and greens and browns from all over the city. People composted like mad... It really created a tremendous sense of camaraderie and community within this core group of people. And now those are the elders. There are now about a handful of people in the garden who are still from those early days. Some of the people in this garden have been here for.... 47 years." Liz explained how this beginning has created a template for activities in the garden. While weekly compost work parties are no longer needed, the infrastructure for conducting projects for the common good still continues.

I asked Liz, "why do you garden?" Liz answered, "I garden to grow food and community. I love to be outdoors, and rather than just go for a walk this is a much richer experience. I've learned so much about food, I feel like I have a really excellent set of food growing skills now, that I can take wherever I go. And I love sharing them.” [Seattle, USA June 2017]

\section{Findings: The superimposition and divergence of the key dimensions of food democracy and the pillars of food sovereignty}

Emulating the narrative style employed by Hassanein (2008), we use this section to outline the four overarching patterns in the embodied actions and expressions of the key dimensions of food democracy and pillars of food sovereignty within the GSR case study - presented in the following subsections as findings $1,2,3$, and 4 . In each subsection, we provide a detailed account of where, and to what extent, the facets of 
each conceptual framework superimpose and diverge across the two data sets. This set of findings reports the results of an iterative thematic data analysis that was performed on the policy documents and the interview data that informed the thick descriptions (see figure 1). The findings were enriched by performing the same analytical technique and coding scheme across the two data sets, as it allowed us to more clearly identify areas where the policy articulations converged and diverged from the lived experiences of the PPatch gardeners. Using these data sources in tandem supports the engagement of perspectives across stakeholder hierarchies (i.e. community experiences and policy instruments) (Hawkes and Halliday 2017). We report findings 1-3 as contextualizing information to foreground the relevance of finding 4 , which is directly material to our argument. The discussion section is framed around an in-depth review of the fourth finding. The characterization of each key dimension/pillar utilized in our coding scheme is described in Table 1.

Table 2: This matrix acts as a guide and a simplified expression for the four findings presented in this section.

\begin{tabular}{|c|c|c|}
\hline Across Data Sets & Pillars of Food Sovereignty & Key dimensions of Food Democracy \\
\hline Superimposed & $\begin{array}{c}\text { Finding 1: } \\
\text { Localize Power; Re-Skilling }\end{array}$ & $\begin{array}{l}\text { Finding 2: } \\
\text { Collaboration; Common Good; } \\
\text { Knowledge }\end{array}$ \\
\hline Divergent & $\begin{array}{l}\text { Finding 3: } \\
\text { Need for Food; Localize Food } \\
\text { System; Support Livelihoods; } \\
\text { Agroecological }\end{array}$ & $\begin{array}{l}\text { Finding 4: } \\
\text { Efficacy; Deliberation }\end{array}$ \\
\hline
\end{tabular}

Finding 1: Pillars of food sovereignty superimposed across both data sets

Our abductive thematic coding process evidenced two out of six pillars of food sovereignty in both the GSR municipal public policy documents and Seattle P-Patch practitioner interviews. They include Localize Power and Re-Skilling, both ranging between 48-52 percent (see Figure 2) representation in each data set. Our coding scheme was informed by the FAO's (Gordilla and Jeronimo 2013) characterization of Localize Power, as described in Table 1. Embodied examples of this pillar of food sovereignty emerged from the policy documents primarily in the form of support for new farmer incubator programs, regional incentives 
to invest in local food system infrastructure, avenues for leasing underutilized city land to urban farmers, and policies to increase market intelligence of regional producers and suppliers (Lerner 2012; King County 2008). Within the lived experience data, Localize Power emerged primarily as practitioners assuming leadership roles within their P-Patch communities, including Liz's role as the Giving Garden manager, individuals collaborating with other regional entities to address issues within the community, and the organization of P-Patch planning groups, such as the one described in Debi's narrative.

The second pillar of food sovereignty evidenced in both data sets, Re-skilling, emerged from the policy documents primarily in the form of capacity-building to address barriers to food security, the promotion of inclusive low impact, chemical-free urban agriculture education, and increased incentives in local jurisdictions to promote healthy eating and local sourcing. Intra-patch workshops, practitioner-organized feedback surveys, and informal community decision-making processes emerged as patterns of re-skilling within the interview data. While our process of analysis coded for re-skilling strictly within the food sovereignty context, the code shares many similarities (and embodied actions/recommendations) with the Knowledge key dimension of food democracy.

\section{Finding 2: Key dimensions of food democracy superimposed across both data sets}

Our process of analysis identifies three of the five key dimensions of food democracy as significantly superimposed across both data sets, including Knowledge, Collaboration, and Common Good. The code Knowledge emerged as superimposed extensively across both data sets, and identified clear conceptual and practical connections with the Re-Skilling pillar of food sovereignty. The return of localized food system knowledge to citizens, coded for as 'Knowledge' (Hassanein 2008), was evidenced most directly within the interview data as extensive networks of practitioner-led knowledge and practice exchanges, both within and across P-Patches, which contributed to further development of contextualized agroecological innovation and knowledge within the P-Patch network. An overarching theme of evolving garden social norms speaks to larger issues of informal knowledge exchange through normative behavior, and the capacity for community discourse to effect action and practice in these urban growing spaces. From the policy perspective, structural efforts to share institutionally-accepted information and practices emerged in the form of introductory education on local sourcing, food waste streams, and ecosystem functioning (Lerner 2012; King County 2008).

The second key dimension of food democracy evidenced widely in both data sets, in many cases bridging knowledge silos across individuals or groups, was collective action by, and among, organizations, 
characterized in our coding scheme as Collaboration (Hassanein 2008). Lived experience data from the Seattle P-Patch network evidenced collaborative action among community groups across a number of scales, including inter-Patch, intra-Patch, and partnerships with both private and municipal entities-such as the informal sharing of resources between the UpGarden gardeners and a nearby senior residential center, and Debi's ongoing garden workshop series with teenagers from a local high school. Similar to the variety of scales upon which collaborative action emerged from the P-Patch network, municipal recommendations put forth by the City of Seattle and King County encouraged and incentivized collaboration between a variety of private and public partners (Lerner 2012; King County 2008).

The last key dimension of food democracy with strong connections in both data sets is an orientation towards the Common Good. This key dimension is evidenced in both individual action and embedded within P-Patch network regulations, ranging from the annual volunteer work required of all practitioners, as outlined in Debi's narrative, to the informal gleaning team donations described by Liz. One overarching pattern across both policy documents is the recommendation for specific collaborative action between the municipal agency and community partners, which endeavor to orient action towards the common good. Occasionally, this promotion of common well-being is related to providing food system education to constituents, linking with the first key dimension of food democracy discussed in this subsection, Knowledge. 
Food Sovereignty:

\section{Representation of FS and FD across the data sets}

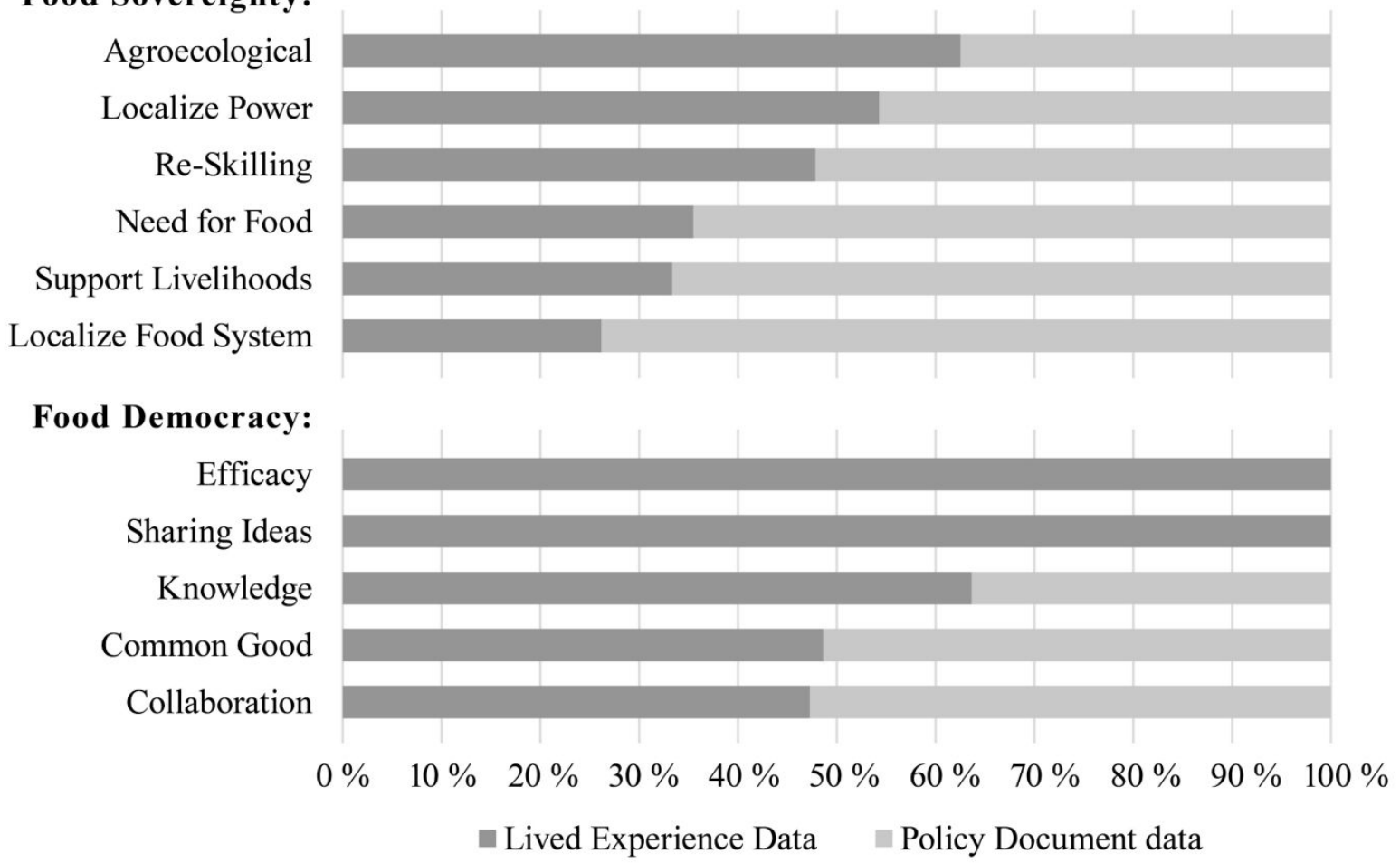

Figure 3: Prevalence of embodied examples of pillars of food sovereignty and key dimensions of food democracy represented across both the lived experience and municipal public policy data.

Finding 3: Pillars of food sovereignty that diverge across both data sets

The four remaining pillars of food sovereignty evidenced a skewed distribution across both data sets, with manifestations of Need for Food, Localize Food System, and Support Livelihoods emerging predominantly from the policy documents, and Agroecological from the interview data. While evidence of the pillar of food sovereignty characterized as Agroecological was indirectly embedded within the policy document data in the form of support for community education that promotes ecosystem resilience, this pillar emerged primarily, and complexly, from the lived experience data. Our interviews with P-Patch gardeners evidenced myriad examples of practitioners engaging with place-based agroecological cultivation methods, shaped by formal and informal exchanges of knowledge and practice within their P-Patch gardens. Supported by the City of Seattle Department of Neighborhoods mandate, which requires organic cultivation in all P-Patch gardens, innovative solutions emerged to resolve location-specific challenges without relying exclusively upon external synthetic inputs. Therefore, embedding the rejection of energy intensive, industrialized 
production methods into the normative behavior of the garden. This rejection was not directly addressed within the policy documents.

In contrast, the three remaining pillars of food sovereignty were found disproportionately represented within the GSR municipal policy recommendations. Abstract linkages with the lived experience data were also present, to a lesser extent. Need for Food emerged from the public policy data primarily in the form of recommendations to engage institutional resources with tackling barriers to regional food security (King County 2008; Lerner 2012). Policy recommendations focused on increasing local jurisdiction incentives to promote access to healthy eating among priority populations, addressing upstream forces contributing to regional food insecurity (including poverty, transportation, and social justice), and improving public nutrition environments in schools, childcare facilities, and city-managed properties (Lerner 2012). While less prevalent, the institutionally-supported Giving Garden Program and practitioner-led Gleaning teams described in Liz and Debi's narratives, in addition to the enrichment of regional food heritage through the local cultivation of culturally-significant foods evidenced in our interviews with other practitioners, also work to place food as a non-commodity, at the heart of action in the P-Patch environment.

Just as the Need for Food pillar of food sovereignty works to place people at the core of policy and action, the Localize Food Systems pillar works to actively reduce the distance between producers and consumers, and rejects dependence upon unaccountable corporations (Gordilla and Jeronimo 2013). The GSR municipal policy articulations recommend a series of strategies to leverage institutional power to incentivize local sourcing, expand access to direct market outlets, and exchange regional agricultural land conservation efforts through leveraging farmland development rights (Lerner 2012; King County 2008). At a smaller scale, a culture of informal harvest sharing present in the P-Patch gardens embody another form of autonomy from spatially disconnected and socially unaccountable corporations.

Lastly, with 68 percent (see Figure 1) representation in the GSR municipal policy documents, is the Support Livelihoods pillar of food sovereignty. Regional GSR public policy harnesses institutional power to support the work of food producers across multiple scales, by providing resources and infrastructure that facilitate new farmer transition out of incubator status, and support new farmers with marketing technical assistance (Lerner 2012). Institutional resources also work to expand the P-Patch garden program, lease unused Cityowned property to urban farmers, streamline permitting services for direct market vendors, and promote market gardens for low-income refugee and immigrant communities (Lerner 2012; King County 2008). While less directly visible in our interviews with P-Patch practitioners, inclusive environments for non- 
able-bodied practitioners, including the Americans with Disabilities Act (ADA) certified raised beds located at UpGarden and other P-Patches, and the wide-spread 'lend a hand' culture present in the gardens also work to support small-scale producers.

Finding 4: Key dimensions of food democracy that diverge across both data sets

Lastly, the two remaining key dimensions of food democracy, Efficacy and Deliberation, were found to be the most polarized between the interview and public policy data sets, manifesting almost exclusively within the lived experience of the practitioners. During our process of analysis, Efficacy was characterized as individuals acting to address and resolve community problems, gaining confidence with their successes (Hassanein 2008). The verbal histories from P-Patch interviewees evidenced politically-charged fights with the City of Seattle for a secure and safe P-Patch location, such as the Interbay campaign described by Liz, which evidences a process by which citizens are engaged in addressing a community challenge, and gaining confidence and capacity with their successes. Collective and self-efficacy is further strengthened in the PPatch network environment through the active empowerment of disenfranchised groups (i.e. disability accommodations as described by Debi, and the network-wide low financial threshold for participation).

Aligning with Hassanein's fourth key dimension of food democracy, we have characterized Deliberation (Sharing Ideas) as the process of open public discussion to navigate ethical dilemmas, which includes sharing ideas related to the food system (2008). As with self-efficacy, this key dimension of food democracy was evidenced exclusively within the lived experience data. Interviewed practitioners described the establishment of shared common values within the P-Patch community through socially negotiated normative behaviors, as well as formal deliberation of decisions directly affecting P-Patch common spaces by community-appointed Intra-Patch committees. Interviews highlighted pathways of informal knowledge exchange, which shape and re-shape organic cultivation practices, whereas place-based cultivation workshops and annual feedback surveys worked to increase the malleability of normative behaviors and practices.

Unlike the opportunities for strengthened individual (and collective) efficacy among practitioners, and the interlocking pathways for structured deliberation among engaged citizens evidenced within the verbal narratives of the practitioners, the municipal public policy documents do not reflect a significant effort to involve direct deliberation with constituents, or create opportunities to directly strengthen constituent efficacy. We, the authors, interpret this polarization as the most significant evidence of what the key dimensions of food democracy can provide to the conceptualization of agroecological urbanism that the 
pillars of food sovereignty, alone, cannot. This finding, supported by the contextualizing evidence presented as findings 1-3, is discussed in relation to the current body of agroecological urbanism literature in the next section.

\section{Discussion: Augmenting the agroecological urbanism discourse}

Despite food sovereignty's entrenched history as a socio-political project emanating from rural, agrarian communities, recent academic discourse working to conceptualize urban agroecology has consistently hinged upon the pillars of food sovereignty (Deh-Tor 2018; García-Sempere et al. 2018; García-Sempere et al. 2019; Vaarst et al. 2018). The application of food sovereignty to an urban, particularly Global North, context is a recognized gap in the current literature (García-Sempere et al. 2018; Deh-Tor 2018).

Contrary to Deh-Tor's (2018) call to bring food sovereignty to an agroecological urbanism, this article questions the capacity of food sovereignty alone to unpack opportunities for food provisioning in urban communities and imaginaries. Echoing the call for 'deep leverage points' for sustainability transformation by Meadows (1999), further developed by Abson et al. (2017), findings 1-4, presented above, illustrate a current state of affairs poised to target necessary, but alone inadequate, entryways to urban food system transformation. The forthcoming comparison between finding 4 of this study and the results of previous research probes the compatibility of the six pillars of the food sovereignty movement with an agroecological production model in order to enable re-localization processes of the urban food system.

Foremost, Vaarst et al. emphasizes 'agroecological food' as the product of agroecological production methods operating within a system built on the basis of agroecological principles (2018). Finding 4 exposes the absence of a 'conceptual bridge' within the food sovereignty framework, which works to vertically link deliberative processes between the urban practitioners who shape, negotiate, and enact contextualized agroecological production methods and the municipal governing structures that facilitate and constrain the scale of their implementation. In exposing this disconnect, finding 4 simultaneously highlights two possibilities drawn from the key dimensions of food democracy to assist in forging such a bridgedeliberation and self-efficacy. In doing so, we argue that the inclusion of mechanisms that enable vertical deliberation up and down the hierarchy of urban food system stakeholders, and the coupled provision of opportunities for strengthened self-efficacy among individuals and community groups, stands to strengthen the nascent architecture of a new paradigm for urbanization built upon the principals of agroecology.

Furthering this argument, Hassanein (2003) points out that sustainable food system transformation will involve conflict over values, for which there is no independent authority to offer a clear resolution. The 
lived experience data from this study highlights the capacity of urban social organization and community building groups to provoke and stimulate horizontal deliberation between residents. This was evidenced by bolded examples within the thick descriptions of practitioner engagement, including Debi's role on the resident planning committee charged with organizing the UpGarden and Liz's recollection of the community-led campaign for a secure location for the Interbay P-Patch after the former site was relocated by the City of Seattle. However, contrary to Vaarst et al. (2018) who emphasize social organization and governmental support as equally critical for agroecological contextualized food systems, finding 4 evidences an absence of governing and institutional structures within the existing GSR municipal public policy that explicitly enable pathways for vertical deliberation up and down the ladder of urban food system stakeholders. This structural barrier may be addressed by regional and state-level policy articulations that expand opportunities for vertical deliberation between food system actors, such as co-created resident engagement processes in municipal planning projects.

In many urban regions, including the site of the case study that informs our research, the provision of land for urban gardening projects is intimately tied with municipal-level urban greenspace planning processes. Indeed, one facet identified to support the shift towards an agroecological urbanism is an increase in planning agency (Tornaghi and Dehaene 2020). As the P-Patch gardens in the GSR operate upon municipal land, they are accounted for and covered under the urban planning authorities at the state and regional level. Finding 4 from this research is useful for urban planning professionals and policy actors involved in land use planning within the contextualized GSR urban agricultural landscape, as it identifies a gap between the lived experience and policy articulations of enacting agroecology in the urban garden setting. Allowing disconnects between policy and practice stands in the way of robust and actionable food system transformation in urban garden settings. By integrating the food democracy dimensions of Efficacy and Deliberation at the policy level, urban planners may be incentivized to experiment with new forms of resident engagement in greenspace planning projects, further integrating the lived experiences and perspectives of practitioners into additional facets of the design of the urban agricultural landscape.

If engaged, urban social movements have the capacity to be significant actors in mobilizing civic participation in regions of condensed political power and decision-making capacity (García-Sempere et al. 2018). While the existing GSR municipal public policy fails to directly enable deliberation between policymakers and grassroots stakeholders seeking to navigate ethical food system dilemmas, as evidenced by finding 4, the P-Patch Community Garden network embodies an urban social group mobilized to participate in shaping their foodshed. 
Mechanisms for horizontal deliberation between practitioners are evidenced across a variety of scales within the network, including inter-and-intra Patch decision-making groups. Evidence that emerged from the practitioner lived experience data-including Liz's growing confidence to assume additional leadership roles at Interbay P-Patch over time and the sense of value and empowerment experienced by Debi at the UpGarden P-Patch-highlights self-efficacy as a product of collaboration and deliberation. Thus, we argue that the capacity to gain confidence in one's ability to overcome contextualized food system challenges is strengthened by each opportunity to engage in deliberative processes, both horizontally and vertically. This suggestion of a positive feedback loop associated with opportunities for deliberative process and development of self-efficacy is worth additional, focused, exploration.

In combination, findings 1-4 suggest that the explicit integration of the two divergent key dimensions of food democracy into the food sovereignty framework-deliberation and self-efficacy-offer a potential course of action to improve the local food planning effort within the GSR. Further, they offer a contribution to the ongoing debate on how to work towards engaging the deep leverage points needed for a revolutionary new paradigm for urbanization grounded in the principles of political agroecology.

\section{Limitations of the Study}

While this research has laid the groundwork for an exploration of the integration of food democracy into the developing articulation of an actionable agroecological urbanism, this research could be bolstered by future studies that have a larger empirical base. Further comparison could be made that evaluates whether the overlaps and divergences of food sovereignty and food democracy manifest in a similar manner in other sets of lived experiences and policy documents, with particular focus placed upon the relationship between deliberative processes and the development of self-efficacy. Additionally, our conclusions should be tested in other urban settings, for example in shrinking, post-industrial, peri-urban, and other urban/city configurations.

\section{Conclusions}

We investigated the addition of the concept of food democracy to the existing food sovereignty discourse present in the nascent conceptualization of an agroecological urbanism. Using a thematic analysis of interview data from urban gardeners in the Seattle P-Patch Community Gardening Program and GSR municipal public policy documents, we explored the manifestations of food sovereignty and food democracy in the lived experiences of practitioners and regional policy articulations. This analysis identified two key dimensions of food democracy that were absent from the food sovereignty framework, 
Efficacy and Deliberation. Both missing dimensions centered on group level processes necessary to discard unsustainable growth patterns and transform food provisioning in the urban context. Group level processes that are present in the lived experience, but absent from the policy documents, include explicit support for vertical deliberation among stakeholders in the food system and pathways to strengthen individual and community self-efficacy. As these group level processes are not directly articulated in the food sovereignty framework, yet they are integrated into the practical experiences of urban gardeners, this supports our hypothesis that the pillars of the rural food sovereignty movement alone are insufficient in describing the lived experience of practitioners engaged in urban agricultural practices. The absence of processes supporting Efficacy and Deliberation in the food sovereignty framework and the policy documents leaves a gap between policy and practice in the articulation of agroecological urbanism. However, when the pillars of food sovereignty are used in concert with the key dimensions of food democracy, the notable gaps of vertical deliberation between food system actors and opportunities for strengthened self-efficacy are addressed. Thus, as the concept of agroecological urbanism gains momentum, we argue that the deliberate inclusion of food democracy as an expanded framing of the socio-cultural aspects of agroecological urbanism, creates a strong set of action-oriented strategies for individual and community level food system transition.

\section{Data Availability Statement}

The data that support the findings of this study are available from the corresponding author, upon reasonable request.

\section{Disclosure Statement}

No potential conflict of interest was reported by the authors.

\section{References:}

Abson, D. et al. 2017. "Leverage points for sustainability transformation." Ambio, 46: 30-39.

Altieri, M. 2018. Agroecology: the science of sustainable agriculture. CRC Press.

Bissell, D., and A. Gorman-Murray. 2019. "[In Press] Disoriented geographies: undoing relations, encountering limits." Transactions of the Institute of British Geographers.

Bouma, J., A.C. Van Altvorst, R. Eweg, P.J.A.M. Smeets, and H.C. Van Latesteijn. 2011. "The role of knowledge when studying innovation and the associated wicked sustainability problems in agriculture.” In Advances in agronomy (Vol. 113, 293-323). Academic Press.

Boyatzis, R. 1998. Transforming qualitative information: Thematic analysis and code development. Sage. 
Cabannes, Y. and C, Marocchino (eds). 2018. Integrating Food into Urban Planning. London, UCL Press; Rome, FAO. Accessed July 2019, https://doi.org/10.14324/111. 9781787353763.

Carlson, J. and Chappell, M.J., 2015. Deepening food democracy. Institute for Agriculture and Trade policy. Accessed April 25, 2020, http://safsf.org/documents/repository/220_04-3015_2015_01_06_Agrodemocracy_JC_JC_f_0.pdf

Chiffoleau, Y., S. Millet-Amrani, and A. Canard. 2016. "From short food supply chains to sustainable agriculture in urban food systems: Food democracy as a vector of transition." Agriculture, 6(4): 57.

Cristofari, H., N. Girard and D. Magda. 2018. "How agroecological farmers develop their own practices: a framework to describe their learning processes." Agroecology and Sustainable Food Systems42, no. 7: 777-795.

Deh-Tor, C.M., M. Dehaene, and C. Tornaghi. 2018. "From Agriculture in the City to an Agroecological Urbanism: The transformative pathway of urban (political) agroecology." Urban Agriculture Magazine, 8-10.

Denzin, N. K. 1994. Handbook of qualitative research. Thousand Oaks, CA: Sage.

Francis, C., G. Lieblein, S. Gliessman, T.A. Breland, N. Creamer, R. Harwood, L. Salomonsson, J. Helenius, D. Rickerl, R. Salvador, and M. Wiedenhoeft. 2003. "Agroecology: The ecology of food systems." Journal of sustainable agriculture, 22(3): 99-118.

García-Sempere, A., H. Morales, M. Hidalgo, B. G. Ferguson, P. Rosset, and A. Nazar-Beutelspacher. 2019. "Food Sovereignty in the city?: A methodological proposal for evaluating food sovereignty in urban settings." Agroecology and Sustainable Food Systems, DOI: 10.1080/21683565.2019.1578719.

García-Sempere, A., Hidalgo, M., Morales, H., Ferguson, B.G., Nazar-Beutelspacher, A. and P. Rosset. 2018. Urban transition toward food sovereignty. Globalizations, 15(3): 390-406.

Gliessman, S. R. and E.W. Engles. 2015. Agroecology: The ecology of sustainable food systems; 3 . Ed. Boca Raton: CRC Press.

Gliessman, S. R. 2018. "Toward a political economy of sustainable food systems." Agroecology and Sustainable Food Systems, 42:10, 1077-1078, DOI: 10.1080/21683565.2018.1497399.

Gliessman, S.R. and P. Tittonell. 2015. "Agroecology for Food Security and Nutrition.” Agroecology and Sustainable Food Systems, 39:2, 131-133, DOI: 10.1080/21683565.2014.972001.

Gordilla, G. and O.M. Jeronimo. 2013. Food security and food sovereignty. FAO. Access date: March 2019. http://www.fao.org/3/a-ax736e.pdf.

Helenius, J., A. Wezel, and C. A. Francis. 2019. "Agroecology." In Oxford Research Encyclopedia of Environmental Science.

Hassanein, N. 2003. "Practicing food democracy: a pragmatic politics of transformation." Journal of rural studies, 19(1): 77-86.

Hassanein, N. 2008. "Locating food democracy: Theoretical and practical ingredients." Journal of Hunger and Environmental Nutrition 3, no. 2-3: 286-308.

Hawkes, C. and J. Halliday. 2017. What makes urban food policy happen? Insights from five case studies. International Panel of Experts on Sustainable Food Systems. www.ipes-food.org.

Holt-Giménez, E. and M.A. Altieri. 2013. "Agroecology, food sovereignty, and the new green revolution.” Agroecology and Sustainable Food Systems, 37(1), 90-102. 
King County. Local Food Initiative: A roadmap to strengthening King County's local food System and increasing access to healthy, affordable food. Seattle: 2008. Print.

Lamine, C. and J. Dawson. 2018. The agroecology of food systems: Reconnecting agriculture, food, and the environment. Agroecology and Sustainable Food Systems, 42(6): 629-636.

Lerner, S. 2012. Seattle food action plan. City of Seattle Office of Sustainability and Environment. Accessed May 2019. http://www.seattle.gov/environment/sustainable-communities/foodaccess/food-action-plan.

Meadows, D. 1999. Leverage points: Places to intervene in a system.Hartland: The Sustainability Institute.

Mendez, V.E, C.M. Bacon, R. Cohen, and S.R. Gliessman. 2013. Agroecology: A transdisciplinary, participatory and action-oriented approach. Boca Raton, Fl. CRC Press.

Miles, M.B. and A.M. Huberman. 1994.Qualitative data analysis: An expanded sourcebook. Thousand Oaks, CA: Sage.

Nicholls, C.I. and M.A. Altieri. 2018. "Pathways for the amplification of agroecology." Agroecology and Sustainable Food Systems, 42(10), 1170-1193.

Nyéléni Declaration. 2007. Nyéléni 2007: Forum for Food Sovereignty, Sélingué, Mali, February 2327, 2007. Accessed August 2019, https://www.nyeleni.org/IMG/pdf/TOWARDS_A_FOOD_SOVEREIGNTY_ACTION_AGENDA II.pdf.

P-Patch Community Garden. Seattle Department of Neighborhoods. Accessed October 2019, https://www.seattle.gov/neighborhoods/programs-and-services/p-patch-community-gardening.

Patel, R. 2009. "Food sovereignty." The Journal of Peasant Studies, 36(3), pp.663-706.

Rosset, P. 2008. "Food sovereignty and the contemporary food crisis." Development, 51(4): 460-463.

Rosset, P.M. and M.E. Martínez-Torres. 2012. "Rural social movements and agroecology: Context, theory, and process." Ecology and Society17(3): 17.

Seattle GeoData. 2018. City of Seattle. P-Patches, Accessed September 2019. http://dataseattlecitygis.opendata.arcgis.com/datasets/9afecc79e1674ccba6508143f6e4ed47_6.

Tornaghi, C. 2014. "Critical geography of urban agriculture.” Progress in Human Geography38(4): 551- 567.

Tornaghi, C. 2017. "Urban Agriculture in the Food-Disabling City: (Re)defining Urban Food Justice, Reimagining a Politics of Empowerment." Antipode 49(3): 781-801.

Tornaghi, C. and M. Dehaene. (2020) The prefigurative power of urban political agroecology: rethinking the urbanisms of agroecological transitions for food system transformation, Agroecology and Sustainable Food Systems, 44:5, 594-610, DOI: 10.1080/21683565.2019.1680593

UN-Habitat. 2016. Urbanization and Development: Emerging Futures. Work Cities Report. Accessed March 2019. http://wcr.unhabitat.org/.

United States Census Bureau. 2018. Seattle City, Washington; United States. Accessed October 2019. https://www.census.gov/quickfacts/fact/table/seattlecitywashington,US/PST045218.

Vaarst, M., A.G. Escudero, M.J. Chappell, C. Brinkley, R. Nijbroek, N. Arraes, L. Andreasen, A. Gattinger, G.F. De Almeida, D. Bossio, N. Halberg. 2018. "Exploring the concept of 
agroecological food systems in a city-region context." Agroecology and Sustainable Food Systems, 42:6, 686-711, DOI: 10.1080/21683565.2017.1365321.

Wezel, A., C. David, A. Ferrer, A. Letort, S. Féret, J. Peigné, J.F. Vian, and F. Celette. 2014. Agroecological practices supporting the provision of goods and services in agriculture: Examples from France and Europe.Rome: Food and Agriculture Organization (FAO).

WinklerPrins, A.M. and P.S. De Souza. 2005. "Surviving the city: urban home gardens and the economy of affection in the Brazilian Amazon." Journal of Latin American Geography, 4(1): 107126. 